\title{
Study Design, Rationale, and Baseline Characteristics: Evaluation of Fenofibric Acid on Carotid Intima-Media Thickness in Patients with Type IIb Dyslipidemia with Residual Risk in Addition to Atorvastatin Therapy (FIRST) Trial
}

\author{
Michael Davidson • Robert S. Rosenson • \\ Kevin C. Maki • Stephen J. Nicholls • \\ Christie M. Ballantyne • Carolyn Setze • \\ Dawn M. Carlson • James Stolzenbach
}

Published online: 24 May 2012

(C) The Author(s) 2012. This article is published with open access at Springerlink.com

\begin{abstract}
Purpose Elevated triglycerides (TG) and low high-density lipoprotein cholesterol (HDL-C) levels contribute to cardiovascular disease risk and can be effectively treated with fenofibric acid. A trial is under way to evaluate the effect of oncedaily fenofibric acid or placebo on carotid intima-media thickness (CIMT) progression in patients with controlled low-
\end{abstract}

M. Davidson $(\bowtie)$

Radiant Research,

515 N. State St., Suite 2700 ,

Chicago, IL 60610, USA

e-mail: MichaelDavidson@RadiantResearch.com

R. S. Rosenson

Mount Sinai School of Medicine,

New York, NY, USA

K. C. Maki

Provident Clinical Research,

Glen Ellyn, IL, USA

\section{S. J. Nicholls}

Cleveland Clinic,

Cleveland, OH, USA

C. M. Ballantyne

Baylor College of Medicine,

Houston, TX, USA

C. M. Ballantyne

Methodist DeBakey Heart and Vascular Center,

Houston, TX, USA

C. Setze $\cdot$ D. M. Carlson $\cdot$ J. Stolzenbach

Abbott Laboratories,

Abbott Park, IL, USA density lipoprotein cholesterol (LDL-C) levels achieved through atorvastatin treatment, but with high $\mathrm{TG}$ and low HDL-C levels.

Methods In this multicenter, double-blind study, 682 patients were randomized to once-daily delayed-release capsules of choline fenofibrate $135 \mathrm{mg}$ (fenofibric acid [Trilipix ${ }^{\circledR}$; Abbott, North Chicago, IL]) or placebo plus atorvastatin treatment after a 2- to 10-week diet and atorvastatin run-in period. Key inclusion criteria included age $\geq 45$ years; posterior-wall common CIMT $\geq 0.7 \mathrm{~mm}$ on at least one side at baseline; fasting results of TG $\geq 150 \mathrm{mg} / \mathrm{dL}$, and HDL-C $\leq 45 \mathrm{mg} / \mathrm{dL}$ for men or HDL$\mathrm{C} \leq 55 \mathrm{mg} / \mathrm{dL}$ for women at screening while receiving atorvastatin; controlled LDL-C; and known coronary heart disease (CHD) or a CHD risk equivalent. The primary efficacy variable is the rate of change from baseline through week 104 in the mean posterior-wall intima-media thickness of the common carotid arteries (composite value of left and right sides). Conclusions This trial is the first to examine the effect of fenofibric acid on CIMT and the first CIMT trial to select patients with controlled LDL-C and elevated TG and low HDL-C as inclusion criteria. Also, this trial will prospectively evaluate the effect of treatment on LDL particles and address shortcomings of previous CIMT trials.

Key words Atorvastatin · CIMT · Dyslipidemia $\cdot$ Fenofibric acid $\cdot$ LDL particle $\cdot$ Triglycerides

\section{Introduction}

Herein we present the rationale and design of a trial with the objective of evaluating the effect of once-daily fenofibric 
acid or placebo, in addition to atorvastatin therapy, on carotid intima-media thickness (CIMT) progression in a population of patients with mixed (type IIb) dyslipidemia who have achieved low-density lipoprotein cholesterol (LDL-C) goals while receiving atorvastatin.

The association of elevated LDL-C with coronary heart disease (CHD) risk and the reduction of LDL-C with statin therapy are well documented. However, it is clear that the reduction of LDL-C by statin therapy alone does not always adequately reduce the risk of cardiovascular disease (CVD). In a review of several studies, Fruchart et al. reported the percentage of residual risk ranges from $63 \%$ to $91 \%$ [1], meaning that even when CVD events are reduced by reaching optimal LDL-C levels with statin therapy, many patients will still experience a CVD event. Factors contributing to residual risk include poor nutrition, lack of exercise, and dysregulation of lipids other than LDL-C (eg, high-density lipoprotein cholesterol [HDL-C] and triglycerides [TG]) [1].

Patients with mixed dyslipidemia (high LDL-C, low HDL-C, and high TG) may benefit from treatments that do more than just primarily lower LDL-C. One such treatment option is fenofibrate, or its active metabolite, fenofibric acid, which increases HDL-C and lowers TG. In a meta-analysis of 18 randomized controlled trials, fibrate monotherapy was found to significantly reduce major cardiovascular (CV) events, coronary events, and non-fatal coronary events compared with placebo [2]. For fenofibrate specifically, results from the ACCORD study determined that of patients treated only with simvastatin, the CVD event rate in the subset of patients with mixed dyslipidemia ( $\mathrm{TG} \geq 204 \mathrm{mg} / \mathrm{dL}$ and HDL-C $\leq 34 \mathrm{mg} / \mathrm{dL}$ ) was quite high compared with the remainder of the patient population $(17.3 \%$ vs $10.1 \%$, respectively); add-on fenofibrate therapy resulted in a lower CVD event rate of $12.4 \%$ in this mixed dyslipidemia subset [3]. In addition, in a post hoc analysis of the FIELD study, an apparent benefit of fenofibrate monotherapy treatment on CVD risk, relative to placebo, in patients with type 2 diabetes treated for a median of 5 years was observed in those with baseline $\mathrm{TG} \geq 204 \mathrm{mg} / \mathrm{dL}$ and HDL-C $<40 \mathrm{mg} / \mathrm{dL}$ for men and $<50 \mathrm{mg} / \mathrm{dL}$ for women [4]. These possible benefits of fenofibrate therapy in the ACCORD and FIELD studies were only observed in the mixed dyslipidemia subgroups, whereas no significant reductions in CVD event rates were observed in the overall study populations [3, 5].

Another meta-analysis that included a total of 4,726 patients from the ACCORD and FIELD studies, as well as 3 studies on the fibrates gemfibrozil and bezafibrate, specifically evaluated treatment effect on coronary outcomes in the subsets of patients with mixed dyslipidemia, defined as $\mathrm{TG} \geq 204 \mathrm{mg} / \mathrm{dL}$ and HDL-C $\leq 34 \mathrm{mg} / \mathrm{dL}$ [6]. The odds of experiencing a CHD event were reduced with fibrate treatment by $35 \%$ compared with placebo in the dyslipidemia cohort, and only $6 \%$ in a matched cohort without dyslipidemia. These data highlight the potential benefit of fibrate treatment for patients with mixed dyslipidemia, but until now, no clinical study has been designed to specifically evaluate the effect of fibrates in this population.

Warnings concerning a possible increased risk for muscle-related adverse events associated with a combination of fibrate and statin have limited its use; however, long-term studies with a choline salt of fenofibric acid or fenofibrate and statin therapy have demonstrated that this combination is generally well tolerated $[3,5,7-11]$. The incidence of muscle-related adverse events was similar between combination treatment and statin monotherapy [9]. Thus, the Food and Drug Administration has approved an indication for the choline salt of fenofibric acid formulated as delayed-release mini-tablets in a capsule (fenofibric acid [Trilipix $\left.{ }^{\circledR}\right]$; Abbott, North Chicago, IL) for use in combination with a statin to reduce TG and increase HDL-C in patients with mixed dyslipidemia and CHD or a CHD risk equivalent who are on optimal statin therapy to achieve their LDL-C goal [12]. Several 12week controlled studies of combination fenofibric acid plus statin therapy have demonstrated significant benefits on HDL-C, TG, non-HDL-C, apolipoprotein (Apo) B, and very low-density lipoprotein cholesterol (VLDL-C) levels compared with statin treatment alone [13-16]. These benefits were maintained for at least 2 years [17] and were also demonstrated in subpopulations of patients with diabetes mellitus or persistently elevated TG [18, 19]. Safety profiles were similar between combination treatments and monotherapies, with no unexpected safety signals relative to each of the monotherapies.

Carotid intima-media thickness is a measure of subclinical atherosclerosis. The association between CVD and CIMT is well established, with abundant evidence that increased CIMT is a risk factor for CV events [20-23]. Predictors of CIMT progression have included elevated TG, non-HDL-C, Apo B, and various lipid ratios in patients with moderate CHD risk [24]. CIMT can also be used as a tool for CVD risk assessment [25-27]. Many CVD drug studies have utilized CIMT as a clinical endpoint, although there are differing opinions on the validity of CIMT as a surrogate marker for outcome studies [28, 29]. A unique aspect of the current study is that it is the first to include only patients with high TG, low HDL-C, and controlled LDL-C. The selection of this patient population will enable further elucidation of the relationship between the pharmacologic modifications of TG and HDL-C, and the progression of atherosclerosis.

A previous study investigated the effect of fenofibrate plus antihypertensive treatment on CIMT in 225 patients with essential hypertension and high TG [30]. After 2 years of combination treatment, CIMT measures either remained 
stable or regressed. In contrast, patients on antihypertensive therapy alone had significant progression of CIMT measures. Also of note, treatment with fenofibrate alone in a study population with type 2 diabetes and normal TG and HDL-C did not affect CIMT, but did significantly reduce TG compared with baseline $(P<0.001)$ [31].

An abundance of small LDL particles is common in patients with elevated TG and low HDL-C. These small particles may be particularly atherogenic because of their greater propensity to enter the arterial wall, where they can undergo oxidation and stimulate endothelial cell production of inflammatory proteins and procoagulants [32]. Uncertainty remains as to whether LDL size is independently associated with CVD risk after adjusting for the LDL particle concentration. The current study will prospectively evaluate the effect of fenofibric acid treatment on LDL particle size and concentration, providing an opportunity to assess the relationships between LDL particle concentration and size, as well as changes in these parameters and risk for CIMT progression.

The current trial was designed to address some of the limitations of previous CIMT trials. For example, patients selected for the trial should be at high risk for CIMT progression and have sufficient CIMT thickness to allow potential for CIMT regression. The lack of a minimum CIMT thickness entry criterion has been suggested as a possible reason patients in the ENHANCE trial did not exhibit significant improvement in CIMT in response to ezetimibe plus simvastatin treatment compared with simvastatin alone [33]. In contrast, other trials with minimum CIMT requirements have demonstrated significant treatment-specific CIMT reductions $[34,35]$. The current trial only includes patients with an increased CIMT (common carotid $\geq 0.7 \mathrm{~mm}$ ) at baseline, which may increase the probability of detecting a treatment effect.

In the current study, particular consideration was given to the assumptions included in the power analysis. Thirteen studies that used simple mean change from baseline (7 studies) or regression models (6 studies) were analyzed to determine the common standard deviation (SD) for the annual progression rate (Table 1) [31, 34-46]. Regressionbased models would generally be expected to result in smaller SDs because they reduce the unexplained variance due to the correlation of the repeated measures within each patient. The median SD from the studies using regression models was substantially lower $(0.028)$ than that for the studies analyzing the simple mean change from baseline (0.076). Thus, the assumption of $\mathrm{SD}=0.045$ in this study is expected to be conservative due to the use of the mixedmodel regression analysis.

The hypothesis for the current study is that patients with mixed dyslipidemia treated with a statin to reach prespecified LDL-C levels, but with persistent high TG and low
HDL-C levels, will experience CIMT benefits from the lipid-altering effects of fenofibric acid.

\section{Methods}

Study design

This is a randomized, multicenter, prospective, doubleblind, placebo-controlled, phase III study of 682 patients in the United States (80 sites in 12 geographic locations; ClinicalTrials.gov identifier: NCT00616772). The planned duration of the study is 118 weeks, composed of a 2 - to 10 week diet and atorvastatin run-in period, a 104-week treatment period, and a 30-day safety follow-up period (Fig. 1). The estimated study completion date is August 2012. Written informed consent was obtained from all patients, and institutional review board approval of the protocol and informed consent form was obtained from each study site.

\section{Key inclusion/exclusion criteria}

Patients meeting the following criteria were included: age $\geq 45$ years at visit 1 ; posterior-wall intima-media thickness (IMT) of the common carotid artery (CCA) $\geq 0.7 \mathrm{~mm}$ on one side at baseline; $\mathrm{TG} \geq 150 \mathrm{mg} / \mathrm{dL}$ and HDL-C $\leq 45 \mathrm{mg} / \mathrm{dL}$ for men or HDL-C $\leq 55 \mathrm{mg} / \mathrm{dL}$ for women after a $\geq 12$-hour fasting period at screening; LDL-C $\leq 100 \mathrm{mg} / \mathrm{dL}$ at visit 1 , 1a, $1 \mathrm{~b}$, or $1 \mathrm{c}$ AND an average of 2 consecutive LDL-C values $\leq 105 \mathrm{mg} / \mathrm{dL}$ from visits $1,1 \mathrm{a}, 1 \mathrm{~b}, 1 \mathrm{c}$, and visit 2 . Patients were also required to have known CHD or a CHD risk equivalent. Patients with any of the following were excluded from the study: systolic blood pressure $>140 \mathrm{~mm}$ $\mathrm{Hg}$ or diastolic blood pressure $>90 \mathrm{~mm} \mathrm{Hg}$ at screening, type 1 diabetes mellitus, diabetic ketoacidosis, or uncontrolled type 2 diabetes mellitus (HbA1c of $>10.5 \%$ ).

\section{Randomization procedure}

A randomization schedule stratified by baseline atorvastatin dose assigned patient numbers to blinded treatment assignments (fenofibric acid or placebo) in a 1:1 ratio. An additional randomization schedule assigned study drug bottle numbers to blinded treatment assignments, and a random subset of study drug bottles were then supplied to each site. At visit 1, the patient was assigned a unique screening number through the use of an Interactive Voice Response System (IVRS). At baseline, the assigned screening number and the current atorvastatin dose was given to the IVRS by the site. The IVRS then assigned a 4-digit patient number and one of the study drug bottle numbers corresponding to the randomized treatment assignment to each patient. 
Table 1 Comparison of baseline lipid levels and mean common CIMT progression rates from clinical studies used to calculate the power analysis standard deviation

\begin{tabular}{|c|c|c|c|c|c|}
\hline Study Treatment & $\begin{array}{l}\text { Mean Baseline } \\
\text { LDL-C }(\mathrm{mg} / \mathrm{dL})^{\mathrm{a}}\end{array}$ & $\begin{array}{l}\text { Mean Baseline } \\
\text { HDL-C }(\mathrm{mg} / \mathrm{dL})^{\mathrm{a}}\end{array}$ & $\begin{array}{l}\text { Mean Baseline } \\
\text { TG }(\mathrm{mg} / \mathrm{dL})^{\mathrm{a}}\end{array}$ & $\begin{array}{l}\text { Treatment Period } \\
\text { Duration }\end{array}$ & $\begin{array}{l}\text { Mean Common } \\
\text { CIMT Change from } \\
\text { Baseline, mm (SD) }\end{array}$ \\
\hline
\end{tabular}

Taylor et al. (2004) [37]

Niacin
Placebo
Difference

$87 \quad 39$

154

12 months

$0.014(0.104)$

$\begin{array}{lll}91 & 40 & 172\end{array}$

$0.044(0.100)$

Difference

Sidhu et al. (2004) [44]

Rosiglitazone

98

45

114

Placebo

102

47

137

Difference

Hanefeld et al. (2004) [46]

\section{Acarbose}

Placebo

Difference

Mazzone et al. (2006) [36]

Pioglitazone

Glimepiride

Difference

Hodis et al. (2006) [42]

Troglitazone

Not

reported

51

212

49

235

Placebo

182

Difference

Hedblad et al. (2007) [41]

Rosiglitazone 13

Placebo

Difference

Crouse et al. (2007) [34]

Rosuvastatin

Placebo

Difference

Kastelein et al. (2007) [38]

Atorvastatin 139

Atorvastatin + torcetrapib $\quad 138$

Difference

Kastelein et al. (2008) [43]

Simvastatin

Simvastatin + ezetimibe

Difference

Hiukka et al. (2008) [31]

$\begin{array}{ll}\text { Fenofibrate } & 120 \\ \text { Placebo } & 118\end{array}$

Difference

Meuwese et al. (2009) [35]

Pactimibe

Placebo

Difference
136

147

135

136
$-0.03$

48 weeks

$-0.012(0.094)$

$0.031(0.096)$

$-0.043$

$0.007(0.019)^{\mathrm{b}}$

$0.013(0.018)^{\mathrm{b}}$

$-0.006^{\mathrm{b}}$

$-0.001$

0.012

$-0.013$

$0.0030(0.021)^{\mathrm{b}}$ $0.0066(0.021)^{\mathrm{b}}$

$-0.0036^{\mathrm{b}}$

$0.01(0.073)$

$0.017(0.076)$

$-0.007$

$0.0004(0.019)^{\mathrm{b}}$

$0.0088(0.02)^{\mathrm{b}}$

$-0.0085^{\mathrm{b}}$

$-0.0014(0.027)^{\mathrm{b}}$

$0.0038(0.027)^{\mathrm{b}}$

$-0.0052^{\mathrm{b}}$

$0.0024(0.077)$

$0.0019(0.079)$

0.0005

$0.0050(0.060)^{\mathrm{b}}$ $0.0069(0.054)^{\mathrm{b}}$

$-0.0019^{\mathrm{b}}$

$0.019(0.099)^{\mathrm{d}}$

$0.005(0.085)^{\mathrm{d}}$

0.014 
Table 1 (continued)

\begin{tabular}{|c|c|c|c|c|c|}
\hline Study Treatment & $\begin{array}{l}\text { Mean Baseline } \\
\text { LDL-C (mg/dL) }\end{array}$ & $\begin{array}{l}\text { Mean Baseline } \\
\text { HDL-C }(\mathrm{mg} / \mathrm{dL})^{\mathrm{a}}\end{array}$ & $\begin{array}{l}\text { Mean Baseline } \\
\mathrm{TG}(\mathrm{mg} / \mathrm{dL})^{\mathrm{a}}\end{array}$ & $\begin{array}{l}\text { Treatment Period } \\
\text { Duration }\end{array}$ & $\begin{array}{l}\text { Mean Common } \\
\text { CIMT Change from } \\
\text { Baseline, mm (SD) }\end{array}$ \\
\hline \multicolumn{6}{|c|}{ Taylor et al. (2009) [45] } \\
\hline Ezetimibe & 84 & 43 & $122^{\mathrm{c}}$ & 14 months & $-0.0007(0.037)$ \\
\hline Niacin & 81 & 43 & $126^{\mathrm{c}}$ & & $-0.0142(0.040)$ \\
\hline Difference & & & & & 0.0135 \\
\hline \multicolumn{6}{|c|}{ Davidson et al. (2009) [40] } \\
\hline Pomegranate juice & 139 & 55 & 153 & 18 months & $0.005(0.048)^{\mathrm{b}}$ \\
\hline Control & 142 & 56 & 144 & & $0.005(0.048)^{\mathrm{b}}$ \\
\hline Difference & & & & & $0.00^{\mathrm{b}}$ \\
\hline
\end{tabular}

$C$ cholesterol; $C I M T$ carotid intima-media thickness; $H D L$ high-density lipoprotein; $L D L$ low-density lipoprotein; $T G$ triglyceride

${ }^{a}$ Reported values in $\mathrm{mmol} / \mathrm{L}$ were converted to $\mathrm{mg} / \mathrm{dL}$ by dividing cholesterol values by 0.02586 and TG values by 0.01130

${ }^{\mathrm{b}}$ Change per year

${ }^{\mathrm{c}}$ Median values

${ }^{\mathrm{d}}$ Included common, bulb, and internal segments

\section{Study phases}

\section{Screening phase}

At visit 1 (prescreening), all patients had a fasting blood sample drawn for blood chemistry, HDL-C, TG, and LDL-C levels. Patients currently taking atorvastatin and with a LDL-C level of $\leq 100 \mathrm{mg} / \mathrm{dL}$ (goal LDL-C) proceeded to visit 2 (screening) within 1 to 2 weeks. Patients currently taking atorvastatin, but with an LDL-C level of $>100 \mathrm{mg} / \mathrm{dL}$, had their atorvastatin dose titrated to reach their LDL-C goals. Up to 3 visits (visit 1a, b, and c) separated by approximately 2 weeks were allowed to achieve the LDL-C goal before proceeding to visit 2 (within 1-2 weeks of achieving the LDL-C goal). Patients not currently taking atorvastatin discontinued other statins and began treatment with atorvastatin, with up to 3 visits (visit 1a, b, and c) approximately
2 weeks apart allowed for dose titration to achieve their LDL-C goal before visit 2 . All patients must have been taking atorvastatin for at least 4 weeks before visit 3 (baseline). During the screening phase, all patients also initiated a diet recommended by the American Heart Association [47].

\section{Treatment phase}

At baseline, patients were randomly assigned to either a oncedaily delayed-release capsule of choline fenofibrate $135 \mathrm{mg}$ (fenofibric acid $\left[\right.$ Trilipix $\left.^{\circledR}\right]$ ) or once-daily placebo in addition to atorvastatin treatment. To maintain an LDL-C value of $<130 \mathrm{mg} / \mathrm{dL}$, investigators reinforced diet requirements and adjusted the atorvastatin dose (maximum dose $40 \mathrm{mg} / \mathrm{d}$ ). The addition of ezetimibe $(10 \mathrm{mg}$ ) was allowed if the patient was already at the maximum atorvastatin dose. To ensure all

Fig. 1 Study design

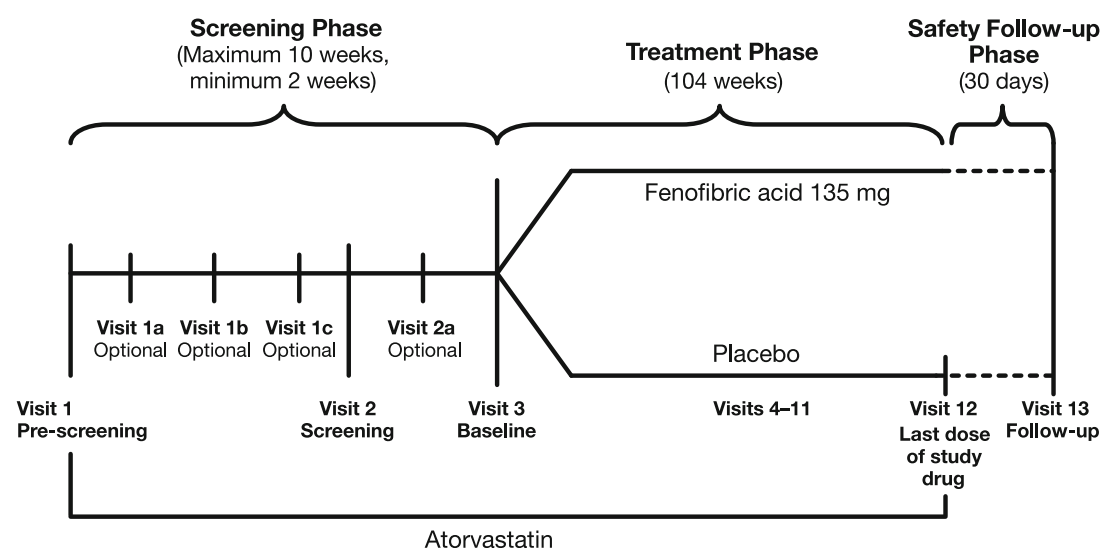


personnel and patients remained blinded following the baseline visit, a central laboratory reviewed LDL-C values and informed the investigator if the atorvastatin treatment required modification. Additional visits were scheduled for weeks 6, 13, 26, 39, 52, 65, 78, 91, and 104.

\section{Safety follow-up phase}

The follow-up phase will begin 1 day after the last dose of study drug and end approximately 30 days later.

Procedures and assessments

\section{Physical examination and laboratory analysis}

A complete physical examination was conducted at baseline and a symptom-directed (per patient report or examiner identified) physical was performed at all subsequent visits. Vital signs, including sitting blood pressure, heart rate, body temperature, and weight, were measured at all visits. Blood and urine were collected at all visits (except no urinalysis at visit 1 ), with a fasting period of at least $12 \mathrm{~h}$ before the blood draw. The lipid and inflammatory parameters to be assessed are listed in Table 2 . A 12-lead resting electrocardiogram (ECG) assessment was performed at baseline and the final visit.

\section{Carotid intima-media thickness}

Carotid intima-media thickness was measured within 17 days before baseline and at weeks 26, 52, 78, and 104 (or upon premature discontinuation). CIMT was only measured upon premature discontinuation if a patient received a minimum of 26 weeks of study drug treatment. The procedure was done by a trained sonographer at a central facility within each of the geographic locations of the participating sites using a standardized protocol (Fig. 2). All facilities used the same device (GE VIVID i equipped with an 8-L probe). A mask tool was used to allow proper repositioning during follow-up visits. After the sonographer selected the region of interest, the CIMT detection and measurement was fully automated.

\section{Safety}

Safety evaluations included physical examinations, vital signs, clinical laboratory testing (hematology, chemistry, and urinalysis), ECG measurements, and adverse event monitoring. Each adverse event was rated by severity and relationship to the study drug.

\section{Compliance}

Compliance with dietary instructions was assessed at all visits following visit 1 based on patient self-reporting. Each patient was asked to return the previously dispensed study drug bottle for documentation of study drug compliance. Patients were considered to be compliant if they adhered to $\geq 80 \%$ of dosing.

\section{Endpoints}

The primary efficacy variable is the rate of change from baseline through week 104 of the mean posterior-wall IMT of the left and right CCAs. The secondary efficacy variables are the rates of change from baseline through week 104 in mean of the maximal posterior-wall IMT of the left and right CCAs and the composite of the CCAs, internal carotid, and carotid bifurcation. Additional efficacy variables include:

Table 2 Lipid and inflammatory markers to be assessed

\begin{tabular}{llc}
\hline Lipid Markers & Inflammatory Markers & Lipid Particle Sizes and Concentrations by NMR Spectroscopy \\
\hline Total-C & hs-CRP & VLDL (total, large, medium and small) \\
LDL-C (direct) & & LDL (total, IDL, large and small) \\
HDL-C & HDL (total, large, medium and small) \\
TG & \\
TG:HDL ratio & \\
Non-HDL-C & \\
VLDL-C & \\
Apo AI & \\
Apo AII & \\
Apo B & \\
Apo B:Apo AII ratio & \\
Apo CIII associated with & \\
Apo B-containing lipoprotein particles &
\end{tabular}

Apo apolipoprotein; $C$ cholesterol; $H D L$ high-density lipoprotein; $h s-C R P$ high-sensitivity C-reactive protein; $I D L$ intermediate-density lipoprotein; $L D L$ low-density lipoprotein; $N M R$ nuclear magnetic resonance; $T G$ triglyceride; $V L D L$ very low-density lipoprotein 
Fig. 2 Scanning protocol

$\mathrm{CCA}=$ common carotid artery;

ICA $=$ internal carotid artery
Scanning depth: $3.5 \mathrm{~cm}^{*}$

\section{Device Settings}

Focal zones: 3

Frequency: $8 \mathrm{MHz}$

Dynamic range 90 , reject 5.0, persistence 1.5, edge enhancement low 0.05

Duration of video clips: 3 cardiac cycles

Supine

Subject Positioning

Head at $45^{\circ}$ angle to side opposite scan

Image oriented so carotid bulb on left and proximal common carotid artery on right Connected to electrocardiograph

Images Acquired

Site

Image type

\begin{tabular}{|l|l|}
\hline Left CCA-near and far wall & Frozen image (only at baseline) \\
\hline Left CCA-near and far wall & Cineloop \\
\hline Right CCA-near and far wall & Frozen image (only at baseline) \\
\hline Right CCA-near and far wall & Cineloop \\
\hline Left bulb-near wall & Frozen image at end of diastole \\
\hline Left bulb-far wall & Frozen image at end of diastole \\
\hline Left ICA-near wall & Frozen image at end of diastole \\
\hline Left ICA-far wall & Frozen image at end of diastole \\
\hline Right bulb-near wall & Frozen image at end of diastole \\
\hline Right bulb-far wall & Frozen image at end of diastole \\
\hline Right ICA-near wall & Frozen image at end of diastole \\
\hline Right ICA-far wall & Frozen image at end of diastole \\
\hline
\end{tabular}

${ }^{*} 4 \mathrm{~cm}$ is acceptable in obese subjects.
1. Rate of change from baseline to week 104 in:

a. Mean of the median, 10th percentile, and 90th percentile posterior-wall IMT of the left and right CCAs

b. Mean cross-sectional area (calculated using posteriorwall IMT and diameter) of the left and right CCAs

2. The occurrence of CV events as a composite of CV mortality, nonfatal myocardial infarction (MI), and nonfatal stroke

3. The occurrence of CV events as a composite of CV mortality, nonfatal MI, nonfatal stroke, coronary revascularization, carotid endarterectomy/stenting, hospitalization for unstable angina, and hospitalization for congestive heart failure

4. Change from baseline in lipid profile and inflammatory markers listed in Table 2

Statistical considerations

Power analysis

A sample size of 300 to 350 patients per group provides $92 \%$ to $95 \%$ power to detect a $0.014 \mathrm{~mm} / \mathrm{y}$ change in CIMT, with a 2 -sided $\alpha$-level of 0.05 , assuming a common standard deviation of $0.045 \mathrm{~mm} / \mathrm{y}$ and allowing for a $25 \%$ dropout rate. The power and sample size were revised from the initial protocol (originally 400 patients per group) based on 1) a reassessment of the literature, resulting in a lower standard deviation for CIMT progression (originally 0.050), and 2) a lower than expected discontinuation rate, resulting in a larger evaluable sample than originally projected.

\section{Outcome analysis}

Means of demographic characteristics will be compared between treatment groups using a one-way analysis of variance (ANOVA). The frequencies and percentages for demographic characteristics will be compared between treatment groups using a chi-square test. Baseline values for CIMT and efficacy laboratory parameters will be compared between treatment groups using a two-way ANOVA with effects for baseline atorvastatin dose and treatment group. Primary, secondary, and additional CIMT variables assessing rates of change will be analyzed using a repeated measures linear mixed-effects model with fixed effects for baseline mean CIMT value, site, baseline atorvastatin dose, treatment group, time, and the interaction between 
treatment group and time. Time to first $\mathrm{CV}$ events will be compared between treatment groups using the log-rank test

Table 3 Demographics and baseline characteristics of the total blinded treated patient population

\begin{tabular}{|c|c|}
\hline Variable & Total Patients $(n=676)$ \\
\hline Male, n (\%) & $458(67.8)$ \\
\hline White race, $\mathrm{n}(\%)$ & $593(87.7)$ \\
\hline \multicolumn{2}{|l|}{ Age } \\
\hline Mean, y (SD) & $60.8(8.75)$ \\
\hline Range, y & $45-87$ \\
\hline Mean BMI, kg/m² (SD) & $32.7(5.81)$ \\
\hline \multicolumn{2}{|l|}{ Nicotine use, $\mathrm{n}(\%)^{\mathrm{a}}$} \\
\hline User & $153(22.7)$ \\
\hline Ex-user & $272(40.3)$ \\
\hline Non-user & $250(37.0)$ \\
\hline \multicolumn{2}{|c|}{ Mean lipid parameters, mg/dL (SD) } \\
\hline Total-C & $157.9(26.2)$ \\
\hline LDL-C (direct) & $84.3(20.9)$ \\
\hline HDL-C & $39.8(7.6)$ \\
\hline TG & $227.5(118.8)$ \\
\hline Non-HDL-C & $118.0(24.9)$ \\
\hline VLDL-C & $41.7(20.4)$ \\
\hline Apo B & $81.0(15.6)$ \\
\hline Apo AI & $130.7(17.9)$ \\
\hline Apo AII & $34.8(5.7)$ \\
\hline Apo CIII-lipoprotein $\mathrm{B}^{\mathrm{b}}$ & $1.6(0.8)$ \\
\hline hs-CRP, mg/L (SD) & $4.1(7.8)$ \\
\hline \multicolumn{2}{|c|}{ Mean HDL particles, $\mu \mathrm{mol} / \mathrm{L}$ (SD) } \\
\hline Total & $32.3(4.9)$ \\
\hline Small & $25.1(5.3)$ \\
\hline Medium & $3.3(3.8)$ \\
\hline Large & $3.9(1.9)$ \\
\hline \multicolumn{2}{|c|}{ Mean LDL particles, nmol/L (SD) } \\
\hline Total & $1,118(277)$ \\
\hline Small & $919(275)$ \\
\hline Large & $153(112)$ \\
\hline IDL & $46(38)$ \\
\hline \multicolumn{2}{|c|}{ Mean VLDL particles, nmol/L (SD) } \\
\hline Total & $93(35)$ \\
\hline Small & $38(17)$ \\
\hline Medium & $48(23)$ \\
\hline Large & $8(7)$ \\
\hline VLDL TG, mg/dL (SD) & $155.4(83.2)$ \\
\hline
\end{tabular}

Apo apolipoprotein; $B M I$ body mass index; $C$ cholesterol; $H D L$ highdensity lipoprotein; $h s-C R P$ high-sensitivity C-reactive protein; $I D L$ intermediate-density lipoprotein; $L D L$ low-density lipoprotein; $T G$ triglyceride; $V L D L$ very low-density lipoprotein

${ }^{a}$ Includes all types of nicotine use

${ }^{\mathrm{b}}$ Apo CIII associated with lipoproteins that contain Apo B, excluding Apo CIII associated with HDL particles stratified by baseline atorvastatin dose. A Cox proportional hazards model with baseline atorvastatin dose as a covariate will be used to obtain the hazard ratio and $95 \%$ confidence interval for the hazard ratio. The percentage changes from baseline in all efficacy laboratory parameters (except highsensitivity C-reactive protein [hs-CRP]) will be analyzed using an analysis of covariance with baseline values (laboratory parameter corresponding to the efficacy variable being modeled) as the covariate and baseline atorvastatin dose and treatment group as effects. A non-parametric analysis will be performed to evaluate the percentage changes from baseline in hs-CRP. Mean changes from baseline in safety laboratory parameters will be compared between treatment groups using a one-way ANOVA. $P$ values $\leq 0.05$ will be considered statistically significant.

\section{Results}

The demographics and baseline characteristics of the study population are shown for the treated patients in Table 3 and clinical characteristics are shown in Table 4. The population is not broken down by treatment group since the study is ongoing, and hence blinded. The characteristics are in alignment with the targeted patient population, although the Apo $B$ level is surprisingly low in relation to LDL-C levels and considering non-HDL-C levels. However, previous CIMT studies may have used different measurements of LDL-C. It is unclear how this parameter will affect the outcome and interpretation of the study.

Table 4 Clinical characteristics of the total blinded treated patient population

\begin{tabular}{lc}
\hline Condition, $n(\%)$ & Total Patients $(n=676)$ \\
\hline Angina & $63(9.3)$ \\
Cardiac arrhythmia & $55(8.1)$ \\
Carotid artery disease & $44(6.5)$ \\
Congestive heart failure & $13(1.9)$ \\
Coronary artery disease & $146(21.6)$ \\
Diabetes type 2 & $337(49.9)$ \\
Emphysema/COPD & $44(6.5)$ \\
Hypertension & $532(78.7)$ \\
Myocardial infarction & $72(10.7)$ \\
Obesity & $193(28.6)$ \\
Peripheral vascular disease, arterial & $16(2.4)$ \\
Peripheral vascular disease, venous & $5(0.7)$ \\
Transient ischemic attack & $13(1.9)$ \\
Valvular heart disease & $16(2.4)$ \\
\hline
\end{tabular}

$C O P D$ chronic obstructive pulmonary disease 


\section{Summary}

In summary, the current study is novel in several ways:

- It is the first study to examine the effect of fenofibric acid on CIMT.

- It is the first CIMT trial to select patients with controlled LDL-C and elevated TG and low HDL-C as inclusion criteria.

- Prospective analysis of LDL particle size and concentrations, as well as Apo B and Apo CIII on Apo Bcontaining lipoprotein particles, may provide more information on the association of these parameters with risk for CIMT progression compared with LDL-C.

- The trial was designed to address some of the limitations of previous CIMT trials.

A beneficial outcome on CIMT after treatment would provide evidence that fenofibric acid can not only improve lipid parameters, but also have a positive effect on progression of subclinical atherosclerosis.

Acknowledgments This study is supported by Abbott. The authors would like to acknowledge the following people for their contribution to designing and/or conducting the study: Linda Balen; Kim Burns; Pauline Kalemba; Dana Kappel; Maureen Kelly, MD; Sarah Leonard; Vicky Paradowski; Deb Schuerr; and Laura Williams, MD. We would also like to acknowledge Aditya Lele and Hsiao-Ming Sun for providing statistical analyses. Editorial and writing assistance was provided by Erin P. Scott, PhD, of Complete Publication Solutions, LLC, and was supported by Abbott.

Funding Source Abbott

Conflict of Interest/Disclosure Information MD has been a consultant and/or participated in advisory boards for Amgen, Merck, Roche, and Sanofi-Aventis, and is a stockholder of Omthera Pharmaceuticals. RSR has received consulting fees from Abbott Laboratories, Amgen, AstraZeneca, F. Hoffman La Roche, Kowa, LipoScience, and Sanofi-Aventis, and his institution receives support from Amgen and Genentech for his research investigations. $\mathrm{KCM}$ has received research funding and/or consulting/speaking fees from Abbott Laboratories, Amarin, Kowa, GlaxoSmithKline, Omthera, Otsuka Pharmaceuticals and Trygg Pharmaceuticals. SJN has been a consultant or received honoraria from Abbott, Anthera, AstraZeneca, Atheronova, Boehringer Ingelheim, CSL, Esperion, Kinemed, Merck, Novo Nordisk, Omthera, Pfizer, Resverlogix, Roche, Sanofi-Aventis, and Takeda, and has received research support from Anthera, AstraZeneca, Eli Lilly, Roche, Novartis, Resverlogix, Karo Bio and LipoScience. CMB has been a consultant, participated in a speaker's bureau, or received honoraria from Abbott, Adnexus, Amylin, AstraZeneca, Bristol-Myers Squibb, Esperion, Genentech, GlaxoSmithKline, Idera Pharma, Kowa, Merck, Novartis, Omthera, Resverlogix, Roche, SanofiSynthelabo, and Takeda, and has received research support from Abbott, AstraZeneca, Bristol-Myers Squibb, diaDexus, GlaxoSmithKline, Kowa, Merck, Novartis, Roche, Sanofi-Synthelabo, and Takeda. CS, DMC, and JS are employees and stockholders of Abbott Laboratories.
Open Access This article is distributed under the terms of the Creative Commons Attribution License which permits any use, distribution, and reproduction in any medium, provided the original author(s) and the source are credited.

\section{References}

1. Fruchart JC, Sacks F, Hermans MP, et al. The residual risk reduction initiative: a call to action to reduce residual vascular risk in patients with dyslipidemia. Am J Cardiol. 2008;102:1K-34K.

2. Jun M, Foote C, Lv J, et al. Effects of fibrates on cardiovascular outcomes: a systematic review and meta-analysis. Lancet. 2010;375:1875-84.

3. Ginsberg HN, Elam MB, Lovato LC, et al. Effects of combination lipid therapy in type 2 diabetes mellitus. N Engl J Med. 2010;362: 1563-74.

4. Scott R, O'Brien R, Fulcher G, et al. Effects of fenofibrate treatment on cardiovascular disease risk in 9,795 individuals with type 2 diabetes and various components of the metabolic syndrome: the Fenofibrate Intervention and Event Lowering in Diabetes (FIELD) study. Diabetes Care. 2009;32:493-8.

5. Keech A, Simes RJ, Barter P, et al. Effects of long-term fenofibrate therapy on cardiovascular events in 9795 people with type 2 diabetes mellitus (the FIELD study): randomised controlled trial. Lancet. 2005;366:1849-61.

6. Sacks FM, Carey VJ, Fruchart JC. Combination lipid therapy in type 2 diabetes. N Engl J Med. 2010;363:692-4; author reply 694-5.

7. Athyros VG, Papageorgiou AA, Athyrou VV, Demitriadis DS, Kontopoulos AG. Atorvastatin and micronized fenofibrate alone and in combination in type 2 diabetes with combined hyperlipidemia. Diabetes Care. 2002;25:1198-202.

8. Durrington PN, Tuomilehto J, Hamann A, Kallend D, Smith K. Rosuvastatin and fenofibrate alone and in combination in type 2 diabetes patients with combined hyperlipidaemia. Diabetes Res Clin Pract. 2004;64:137-51.

9. Grundy SM, Vega GL, Yuan Z, et al. Effectiveness and tolerability of simvastatin plus fenofibrate for combined hyperlipidemia (the SAFARI trial). Am J Cardiol. 2005;95:462-8.

10. Koh KK, Quon MJ, Han SH, et al. Additive beneficial effects of fenofibrate combined with atorvastatin in the treatment of combined hyperlipidemia. J Am Coll Cardiol. 2005;45:1649-53.

11. Bays HE, Jones PH, Mohiuddin SM, et al. Long-term safety and efficacy of fenofibric acid in combination with statin therapy for the treatment of patients with mixed dyslipidemia. J Clin Lipidol. 2008;2:426-35.

12. Trilipix ${ }^{\circledR}$ (fenofibric acid delayed release capsules). Full prescribing information. North Chicago: Abbott Laboratories; 2008.

13. Goldberg AC, Bays HE, Ballantyne CM, et al. Efficacy and safety of ABT-335 (fenofibric acid) in combination with atorvastatin in patients with mixed dyslipidemia. Am J Cardiol. 2009; 103:515-22.

14. Jones PH, Davidson MH, Kashyap ML, et al. Efficacy and safety of ABT-335 (fenofibric acid) in combination with rosuvastatin in patients with mixed dyslipidemia: a phase 3 study. Atherosclerosis. 2009;204:208-15.

15. Mohiuddin SM, Pepine CJ, Kelly MT, et al. Efficacy and safety of ABT-335 (fenofibric acid) in combination with simvastatin in patients with mixed dyslipidemia: a phase 3, randomized, controlled study. Am Heart J. 2009;157:195-203.

16. Roth EM, Rosenson RS, Carlson DM, et al. Efficacy and safety of rosuvastatin $5 \mathrm{mg}$ in combination with fenofibric acid $135 \mathrm{mg}$ in patients with mixed dyslipidemia - a phase 3 study. Cardiovasc Drugs Ther. 2010;24:421-8. 
17. Kipnes MS, Roth EM, Rhyne JM, et al. Year two assessment of fenofibric acid and moderate-dose statin combination. Clin Drug Investig. 2010;30:51-61.

18. Ballantyne CM, Jones PH, Kelly MT, et al. Long-term efficacy of adding fenofibric acid to moderate-dose statin therapy in patients with persistent elevated triglycerides. Cardiovasc Drugs Ther. 2011;25:59-67.

19. Rosenson RS, Carlson DM, Kelly MT, et al. Achievement of lipid targets with the combination of rosuvastatin and fenofibric acid in patients with type 2 diabetes mellitus. Cardiovasc Drugs Ther. 2011;25:47-57.

20. Chambless LE, Heiss G, Folsom AR, et al. Association of coronary heart disease incidence with carotid arterial wall thickness and major risk factors: the Atherosclerosis Risk in Communities (ARIC) Study, 1987-1993. Am J Epidemiol. 1997;146: 483-94.

21. Li C, Engstrom G, Berglund G, Janzon L, Hedblad B. Incidence of ischemic stroke in relation to asymptomatic carotid artery atherosclerosis in subjects with normal blood pressure. A prospective cohort study. Cerebrovasc Dis. 2008;26:297-303.

22. Lorenz MW, Markus HS, Bots ML, Rosvall M, Sitzer M. Prediction of clinical cardiovascular events with carotid intima-media thickness: a systematic review and meta-analysis. Circulation. 2007;115:459-67.

23. O'Leary DH, Polak JF, Kronmal RA, et al. Carotid-artery intima and media thickness as a risk factor for myocardial infarction and stroke in older adults. Cardiovascular Health Study Collaborative Research Group. N Engl J Med. 1999;340:14-22.

24. Maki KC, Davidson MH, Dicklin MR, et al. Predictors of anterior and posterior wall carotid intima media thickness progression in men and women at moderate risk of coronary heart disease. J Clin Lipidol. 2011;5:141-51.

25. Nambi V, Chambless L, Folsom AR, et al. Carotid intima-media thickness and presence or absence of plaque improves prediction of coronary heart disease risk: the ARIC (Atherosclerosis Risk In Communities) study. J Am Coll Cardiol. 2010;55:1600-7.

26. Nambi V, Chambless L, He M, et al. Common carotid artery intima-media thickness is as good as carotid intima-media thickness of all carotid artery segments in improving prediction of coronary heart disease risk in the Atherosclerosis Risk in Communities (ARIC) study. Eur Heart J. 2012;33:183-90.

27. Polak JF, Pencina MJ, Pencina KM, et al. Carotid-wall intimamedia thickness and cardiovascular events. N Engl J Med. 2011;365:213-21.

28. Costanzo P, Perrone-Filardi P, Vassallo E, et al. Does carotid intima-media thickness regression predict reduction of cardiovascular events? A meta-analysis of 41 randomized trials. J Am Coll Cardiol. 2010;56:2006-20.

29. Espeland MA, O'Leary DH, Terry JG, et al. Carotid intimal-media thickness as a surrogate for cardiovascular disease events in trials of HMG-CoA reductase inhibitors. Curr Control Trials Cardiovasc Med. 2005;6:3.

30. Zhu S, Su G, Meng QH. Inhibitory effects of micronized fenofibrate on carotid atherosclerosis in patients with essential hypertension. Clin Chem. 2006;52:2036-42.

31. Hiukka A, Westerbacka J, Leinonen ES, et al. Long-term effects of fenofibrate on carotid intima-media thickness and augmentation index in subjects with type 2 diabetes mellitus. J Am Coll Cardiol. 2008;52:2190-7.
32. Kwiterovich Jr PO. Clinical relevance of the biochemical, metabolic, and genetic factors that influence low-density lipoprotein heterogeneity. Am J Cardiol. 2002;90:30i-47i.

33. Davidson MH, Dembowski E. Atherosclerosis surrogate imaging trials come of age: for better or for worse? Curr Cardiol Rep. 2008; 10:521-5.

34. Crouse 3rd JR, Raichlen JS, Riley WA, et al. Effect of rosuvastatin on progression of carotid intima-media thickness in low-risk individuals with subclinical atherosclerosis: the METEOR Trial. JAMA. 2007;297:1344-53.

35. Meuwese MC, de Groot E, Duivenvoorden R, et al. ACAT inhibition and progression of carotid atherosclerosis in patients with familial hypercholesterolemia: the CAPTIVATE randomized trial. JAMA. 2009;301:1131-9.

36. Mazzone T, Meyer PM, Feinstein SB, et al. Effect of pioglitazone compared with glimepiride on carotid intima-media thickness in type 2 diabetes: a randomized trial. JAMA. 2006;296:2572-81.

37. Taylor AJ, Sullenberger LE, Lee HJ, Lee JK, Grace KA. Arterial Biology for the Investigation of the Treatment Effects of Reducing Cholesterol (ARBITER) 2: a double-blind, placebo-controlled study of extended-release niacin on atherosclerosis progression in secondary prevention patients treated with statins. Circulation. 2004;110:3512-7.

38. Kastelein JJ, van Leuven SI, Burgess L, et al. Effect of torcetrapib on carotid atherosclerosis in familial hypercholesterolemia. N Engl J Med. 2007;356:1620-30.

39. Davidson M, Meyer PM, Haffner S, et al. Increased high-density lipoprotein cholesterol predicts the pioglitazone-mediated reduction of carotid intima-media thickness progression in patients with type 2 diabetes mellitus. Circulation. 2008;117:2123-30.

40. Davidson MH, Maki KC, Dicklin MR, et al. Effects of consumption of pomegranate juice on carotid intima-media thickness in men and women at moderate risk for coronary heart disease. Am J Cardiol. 2009; 104:936-42.

41. Hedblad B, Zambanini A, Nilsson P, Janzon L, Berglund G. Rosiglitazone and carotid IMT progression rate in a mixed cohort of patients with type 2 diabetes and the insulin resistance syndrome: main results from the Rosiglitazone Atherosclerosis Study. J Intern Med. 2007;261:293-305.

42. Hodis HN, Mack WJ, Zheng L, et al. Effect of peroxisome proliferator-activated receptor gamma agonist treatment on subclinical atherosclerosis in patients with insulin-requiring type 2 diabetes. Diabetes Care. 2006;29:1545-53.

43. Kastelein JJ, Akdim F, Stroes ES, et al. Simvastatin with or without ezetimibe in familial hypercholesterolemia. N Engl J Med. 2008;358:1431-43.

44. Sidhu JS, Kaposzta Z, Markus HS, Kaski JC. Effect of rosiglitazone on common carotid intima-media thickness progression in coronary artery disease patients without diabetes mellitus. Arterioscler Thromb Vasc Biol. 2004;24:930-4.

45. Taylor AJ, Villines TC, Stanek EJ, et al. Extended-release niacin or ezetimibe and carotid intima-media thickness. N Engl J Med. 2009;361:2113-22.

46. Hanefeld M, Chiasson JL, Koehler C, et al. Acarbose slows progression of intima-media thickness of the carotid arteries in subjects with impaired glucose tolerance. Stroke. 2004;35:1073-8.

47. American Heart Association. Making healthy food and lifestyle choices. Dallas: American Heart Association; Publication No. 50 $1541 ; 2006$. 